\title{
CONTACT SENSITIZATION TO INGREDIENTS OF DENTAL MATERIALS AND COSMETICS IN DENTAL STUDENTS: A PILOT STUDY
}

\author{
Maya Grigorievna Lyapina1, Maria Stoyanova Dencheva² \\ ${ }^{1}$ Medical College I. Filaretova, Medical University, Sofia, Bulgaria \\ ${ }^{2}$ Department of Oral and Image Diagnostic, Faculty of Dental Medicine, Medical University, Sofia, Bulgaria
}

\section{SUMMARY}

Objective: The aim of this study was to evaluate the rate of contact sensitization to selected cosmetic allergens, i.e. ingredients of dental materials, in students of dental medicine and dental patients.

Methods: A total of 50 participants were included in the study: 40 students of dental medicine exposed to the studied allergens during the course of practical education; and 10 randomly selected dental patients without occupational exposure to the investigated substances served as a control group. All of them were patch-tested with colophonium, myroxylon pereirae resin, paraben mix, fragrance mix I, isopropyl myristate, triclosan, polysorbate 80 , compositae mix II, and hydroperoxides of limonene.

Results: The sensitization rates for colophonium and polysorbate 80 were the highest. For the group of dental students, we established significantly higher sensitization rate for colophonium compared to the ones for myroxylon pereirae resin and hydroperoxides of limonene $\left(x^{2}=4.93 ; p=\right.$ 0.026), paraben mix $\left(x^{2}=3.6 ; p=0.05\right)$, isopropyl myristate $\left(x^{2}=6.56 ; p=0.01\right)$, and triclosan $\left(x^{2}=8.5 ; p<0.001\right)$; and to polysorbate 80 compared to the ones for myroxylon pereirae resin and hydroperoxides of limonene $\left(x^{2}=3.97 ; p=0.046\right)$, isopropyl myristate $\left(x^{2}=5.47 ; p=0.02\right)$ and triclosan $\left(X^{2}=7.34 ; p=0.007\right)$. Significantly increased concomitant sensitization rate to compositae mix and to hydroperoxides of limonene was established $\left(X^{2}=12.55 ; p<0.001\right)$. Generally, the incidence of concomitant sensitization to the studied allergens in the whole studied population was high.

Conclusions: Colophonium and polysorbate 80 could be outlined as sensitizers of paramount importance for both dental students and dental patients. We consider the major importance of exposure to colophonium during the course of practical education in dentistry for the onset of the sensitization. Sensitization to compositae mix was observed only among dental students. We consider the leading role of consumer exposure for the onset of the sensitization to triclosan and to hydroperoxides of limonene. Unexpected and unreported reactions of concomitant sensitization were observed.

Key words: contact sensitization, students of dental medicine, colophonium, myroxylon pereirae resin, paraben mix, fragrance mix I, isopropyl myristate, triclosan, polysorbate 80 , compositae mix II, hydroperoxides of limonene

Address for correspondence: M. Lyapina, Medical College I. Filaretova, Medical University, I. Filaretova str., 1606 Sofia, Bulgaria. E-mail: saly_grigory@abv.bg

https://doi.org/10.21101/cejph.a4756

\section{INTRODUCTION}

Dental professionals are occupationally exposed to numerous chemical substances as ingredients of various dental materials (e.g. methacrylates, metals), medicinal products, medicines, disinfectants, hand wash products, etc., many of which represent both allergens and irritants. This exposure occurs during the course of their practical education in dentistry and their professional activity.

There is an impressive array of cosmetic products available on the market today, and the number of new products continues to increase. Their main ingredients can be classified into fragrances, preservatives, vehicles, ultraviolet absorbers, emollients, emulsifiers, acrylates, and others (1). It is estimated that $1-5.4 \%$ of the population is sensitized to cosmetic or cosmetic ingredient. The most frequently identified cosmetic allergens are fragrances $(2$, 3). Many of them are ingredients of dental materials and products for use in dentistry as well.
Plant resins (colophonium and myroxylon pereirae mix) are also known sensitizers, common ingredients of both cosmetic products and dental materials (4). The spectrum of colophonium (also known as rosin) applications is immense. In dentistry it is a component in dental impression materials and periodontal packings (5). Myroxylon pereirae mix (balsam of Peru) has 3 main uses: fragrance in perfumes and toiletries, flavouring in food and drinks, and healing properties in medicinal products (6). Parabens are the most commonly used preservatives in topical pharmaceutical preparations and in cosmetics (7). Triclosan is used as an antimicrobial agent in personal care products such as toothpastes, mouth washes and antibacterial soaps, and also in consumer products such as cleaning products, plastics and toys (8). Isopropyl myristate is a popular cosmetic, oral hygiene products and pharmaceutical ingredient, synthetic oil used as an emollient, thickening agent or lubricant, a clinically relevant cosmetic series allergen (9). Polysorbate 80 is emulsifier and 
dispersing agent for medicinal products for internal use that could induce hypersensitivity reactions (10). Compositae contact allergy refers to allergic reactions caused by a group of plants commonly known as Compositae, an alternative name for the official term Asteraceae. Limonene is a naturally occurring terpene, present in large amounts in various citrus fruits (11). According to the study of Toholka et al., among the top 20 allergens were fragrance mix 1, Myroxylon pereirae, colophony (rosin), and Compositae mix (12).

According to the European Agency for Safety and Health at Work (EU-OSHA), statistics show that 18- to 24-year-olds might be at risk of the development of occupational illnesses while still young or later in life. New to the workplace, young people may lack experience and often lack both physical and psychological maturity. They may not take seriously enough the risks they face (13). Our previous studies indicate increased incidence of sensitization to substances relevant for everyday dental practice among dental students (14-18), so according to our own experience we could outline this group as a vulnerable one.

The aim of the present study was to evaluate the rate of contact sensitization to selected cosmetic allergens, i.e. ingredients of dental materials, in students of dental medicine and dental patients, and to identify a possible risk of early onset of sensitization after 3-6 years of exposure during the practical training in dentistry.

\section{MATERIALS AND METHODS}

\section{Subjects}

A total of 50 participants were included in the study: 40 students of dental medicine (19 males and 21 females, mean age $25.30 \pm 4.1$ ), exposed to the selected substances listed below, i.e. ingredients of both products relevant to the exposure of general population (cosmetics) and dental materials and products used during the course of their practical education (Group A); and 10 randomly selected dental patients (4 males and 6 females, mean age $47.70 \pm 17.6$ ), without occupational exposure to the investigated substances served as a control group (Group B). The study was approved by the Medical Ethics Board at Medical University, Sofia. All participants were informed about the purpose of the study and gave their written informed consent.

\section{Methods}

Skin patch testing with colophonium (20.0\%/pet), myroxylon pereirae resin $(25.0 \% /$ pet $)$, paraben mix $(12.0 \% /$ pet $)$, fragrance mix I $(8.0 \% /$ pet $)$, isopropyl myristate $(20.0 \% /$ pet $)$, triclosan $(2.0 \% /$ pet $)$, polysorbate $80(5.0 \% /$ pet $)$, compositae mix II $(5.0 \% /$ pet), and hydroperoxides of limonene $(0.2 \%$ /pet, Chemotechnique Diagnostics) was performed according to the Jadassohn-Bloch classical methods for diagnosis of contact allergy, by placing the allergens in IQ-Ultra hypoallergenic patches of Chemotechnique Diagnostics (IQ Chambers ${ }^{\circledR}$, Vellinge, Sweden). Lack of antiallergic medication constituted a mandatory condition before placing the patches and during the testing. Patches with allergens were applied on the back of the tested individuals, reading of the test was performed after 48 hours exposure, followed by control reactions reading in 72 and 96 hours after patch test removal. For the interpretation of the test result the following scheme was used (International Contact Dermatitis Research Group - ICDRG):

(-) Negative reaction

? Doubtful reaction

+ Weak reaction (non-vesicular)

++ Strong reaction (oedematous or vesicular)

+++ Extreme reaction (ulcerative or bullous)

IR Irritant reaction

Weak, strong and extreme reactions were classified as positive; and negative, irritant and doubtful reactions as non-positive.

\section{Statistical Analysis}

The statistics were calculated mainly with SPSS 19.0. Comparing two independent proportions (comparison of proportions), expressed as a percentage of the relevant sample, the so-called „N1" Chi-squared test, Campbell (2007) and Richardson (2012) was used. Values of $\mathrm{p}<0.05$ were considered statistically significant.

\section{RESULTS}

Data concerning the incidence of positive patch test reactions to the studied substances in the investigated groups are summarized in Table 1. The highest sensitization rates for both defined groups were for colophonium and polysorbate 80 . A significantly

Table 1. Distribution of positive skin patch test reactions to studied allergens among studied groups $(N=50)$

\begin{tabular}{|l|c|c|c|}
\hline Allergen & $\begin{array}{c}\text { Positive reactions } \\
\text { in Group } \mathbf{A}(\mathbf{n}=40) \\
\mathbf{n}(\%)\end{array}$ & $\begin{array}{c}\text { Positive reactions } \\
\text { in Group B }(\mathbf{n}=10) \\
\mathbf{n}(\%)\end{array}$ & $\begin{array}{c}\text { Positive reactions } \\
\text { Total } \\
\mathbf{N}(\%)\end{array}$ \\
\hline Colophonium & $12(30.0)$ & $1(10.0)$ & $13(26.0)$ \\
\hline Myroxylon pereirae resin & $4(10.0)$ & $1(10.0)$ & $5(10.0)$ \\
\hline Paraben mix & $5(12.5)$ & $1(10.0)$ & $6(12.0)$ \\
\hline Fragrance mix I & $7(17.5)$ & $1(10.0)$ & $9(18.0)$ \\
\hline Isopropyl myristate & $3(7.5)$ & $1(10.0)$ & $4(8.0)$ \\
\hline Triclosan & $2(5.0)$ & $2(20.0)$ & $4(8.0)$ \\
\hline Polysorbate 80 & $11(27.5)$ & $1(10.0)$ & $12(24.0)$ \\
\hline Compositae mix & $6(15.0)^{*}$ & - & $6(12.0)$ \\
\hline Hydroperoxides of limonene & $4(10.0)$ & $2(20.0)$ & $6(12.0)$ \\
\hline
\end{tabular}


Table 2. Distribution of concomitant sensitization to studied allergens in dental students and whole population $(N=50)$

\begin{tabular}{|c|c|c|c|c|c|c|c|c|c|c|c|c|c|c|c|c|c|c|}
\hline & \multicolumn{9}{|c|}{ Dental students $(n=40)$} & \multicolumn{9}{|c|}{ Whole population $(n=50)$} \\
\hline Allergen & 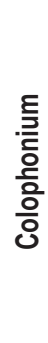 & 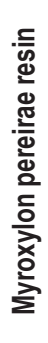 & 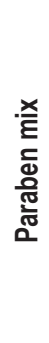 & 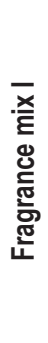 & 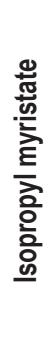 & $\begin{array}{l}\text { 듀 } \\
\text { 은 } \\
\text { 은 }\end{array}$ & 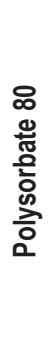 & 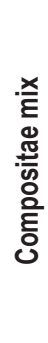 & 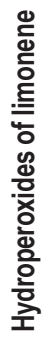 & 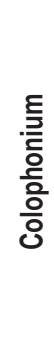 & 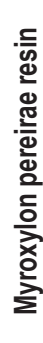 & 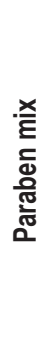 & 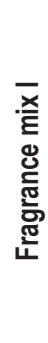 & 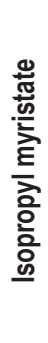 & $\begin{array}{l}\text { ్ㅠ } \\
\text { 은 } \\
\text { 은 }\end{array}$ & 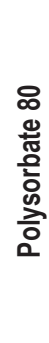 & 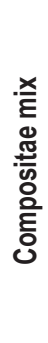 & 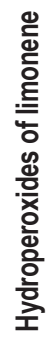 \\
\hline Colophonium & 12 & 1 & - & 2 & 2 & - & 4 & 2 & 1 & 13 & 1 & 1 & 2 & 2 & - & 4 & 2 & 2 \\
\hline Myroxylon pereirae resin & 1 & 4 & - & 1 & - & - & 2 & 1 & - & 1 & 5 & - & 1 & - & - & 2 & 1 & - \\
\hline Paraben mix & - & - & 5 & 1 & - & - & - & 4 & - & 1 & - & 6 & 1 & - & - & - & - & 1 \\
\hline Fragrance mix I & 2 & 1 & 1 & 7 & - & - & 3 & 1 & - & 2 & 1 & 1 & 7 & - & - & 3 & 1 & - \\
\hline Isopropyl myristate & 2 & - & - & - & 3 & - & - & - & - & 2 & - & - & - & 4 & - & - & - & - \\
\hline Triclosan & - & - & - & - & - & 2 & 2 & 1 & 1 & - & - & - & - & - & 4 & 3 & 1 & 2 \\
\hline Polysorbate 80 & 4 & 2 & - & 3 & - & 2 & 11 & 1 & 2 & 4 & 2 & - & 3 & - & 3 & 12 & 3 & 2 \\
\hline Compositae mix & 2 & 1 & - & 1 & - & 1 & 3 & 6 & 3 & 2 & 1 & - & 1 & - & 1 & 3 & 6 & 3 \\
\hline $\begin{array}{l}\text { Hydroperoxides of } \\
\text { limonene }\end{array}$ & 1 & - & - & - & - & 1 & 2 & 1 & 4 & 2 & - & 1 & - & - & 2 & 2 & 3 & 6 \\
\hline
\end{tabular}

increased incidence of sensitization to colophonium, if compared to myroxylon pereirae resin and hydroperoxides of limonene $\left(\chi^{2}=4.93 ; \mathrm{p}=0.026\right)$, paraben mix $\left(\chi^{2}=3.6 ; \mathrm{p}=0.05\right)$, isopropyl myristate $\left(\chi^{2}=6.56 ; \mathrm{p}=0.01\right)$, and triclosan $\left(\chi^{2}=8.5 ; \mathrm{p}<0.001\right)$ was established amongst dental students. For this group, we revealed significantly increased sensitization to polysorbate 80 , if compared to myroxylon pereirae resin and hydroperoxides of limonene $\left(\chi^{2}=3.97 ; p=0.046\right)$, isopropyl myristate $\left(\chi^{2}=5.47\right.$; $\mathrm{p}=0.02)$ and to triclosan $\left(\chi^{2}=7.34 ; \mathrm{p}=0.007\right)$.

Furthermore, for the whole studied population, the incidence of sensitization to colophonium was significantly higher compared to myroxylon pereirae resin $\left(\chi^{2}=4.29 ; p=0.038\right)$ and to isopropyl myristate and riclosan $\left(\chi^{2}=5.6 ; \mathrm{p}=0.017\right)$.

The distribution of concomitant sensitization to substances included in the study in the group of dental students and among all tested individuals is presented in Table 2. The incidence of concomitant sensitization to compositae mix and to hydroperoxides of limonene $\left(\chi^{2}=12.55 \mathrm{p}<0.001\right)$ was significantly higher. Generally, the incidence of concomitant sensitization to the studied allergens among all tested subjects was high $-26 \%$ had positive skin patch test reactions to 3 allergens, $24 \%$ to $2,14 \%$ to 5 , and $12 \%$ to 4 . Positive skin patch test reactions were not recorded only among two individuals.

\section{DISCUSSION}

It is difficult to estimate the frequency of adverse reaction to cosmetics ingredients in the general population, and it is most likely underestimated due to the fact that most people do not seek medical advice and simply discontinue to use the product suspected of triggering a reaction.

Plant resins are uniquely different in composition from other plant-based secretions. They ward off pathogens, insects and other animals by sealing puncture sites on the tree and have antiseptic properties. Colophonium is the term collectively used for the solidified, distilled form of resins from pines, cedars, spruce, firs, and junipers (19). Its pervasiveness likely contributes to its ranking as No. 1 of the top 10 allergens in many countries and makes it an important source of occupational contact dermatitis (20). Colophonium is commonly found in dentistry products, namely sealants and topical medications. One of the principle components of neoprene surgical gloves is colophony (21). According to our results, the highest was the incidence of sensitization to colophonium (30\%) for the group of dental students, with statistical significance, compared to myroxylon pereirae resin, hydroperoxides of limonene, paraben mix, isopropyl myristate, and triclosan. We could suggest a major importance of the exposure to colophonium during the course of practical education in dentistry for sensitization onset. Balsam of Peru is the most widely used marker for diagnosis of fragrance allergy. This natural resin extracted from Myroxylon pereirae, a tree that grows in Central and South America, was originally used to heal wounds and cure infections. It can be found in perfumes, cleaning products, topical medications, dental cements, root canal fillings and impression materials, cosmetic products, and food aroma compounds. Balsam of Peru is composed of 250 chemical substances, some fragrance allergens (e.g. cinnamyl alcohol, cinnamic aldehyde, eugenol, and isoeugenol). Cross-reactions may occur to colophonium and fragrance mix I (22). According to Belloni et al., myroxylon pereirae resin is among the 10 most frequent haptens (20). Our findings do not confirm these results - the established sensitization rate was $10 \%$ for both defined groups. Single cases of concomitant sensitization to myroxylon pereirae resin and the other allergens included in the present pilot study were observed. Based on the results achieved, we cannot consider it as a significant and concomitantly reacting sensitizer for dental students. Fragrances were declared the Contact Allergen of the Year for 2007 by the 
American Contact Dermatitis Society. Available tools to assess fragrance allergy are fragrance mix I and fragrance mix II. Recently, the highest prevalence of contact allergy in the general population of five European countries was found for fragrance mix I (23). In the present pilot study, we performed patch testing with fragrance mix I, since it includes eugenol - a widely used as an ingredient in personal hygiene products, toothpastes, mouthwash, pharmaceutical creams for its antiseptic properties, as well as in dental cement, impression materials and periodontal packings, thus giving the characteristic odour of dental surgeries. Cross-reactions with Peru balsam were described. In our study, fragrance mix I was ranked as the third important allergen for dental students with sensitization rate of $17.5 \%$. No significant cross-reactivity with Peru balsam was revealed. Polysorbate 80 is emulsifier and dispersing agent used in numerous cosmetics and foods, as well as in dentistry - in endodontic irrigants for disinfection, mouthwashes, and multiple medical preparations (24). Surprisingly, in our study polysorbate 80 was found to be the second important allergen for dental students with sensitization rate of $27.5 \%$ - significantly higher compared to myroxylon pereirae resin, hydroperoxides of limonene, isopropyl myristate, and triclosan. Moreover, $36.4 \%$ of dental students with positive skin patch tests to polysorbate 80 were sensitized to colophonium as well, and $27.8 \%$ of these students were concomitantly sensitized to fragrance mix I. No similar data was found in the available literature. This is a pilot study and the investigated sample is too small to give a categorical statement on these findings. Cross-reactivity between compositae allergens and balsam of Peru, colophonium, essential oils and fragrances was described by Paulsen and Andersen (25). We established a relatively high sensitization rate to compositae mix $-15 \%$, with positive patch tests observed only among dental students. No similar results were reported. Moreover, our findings confirm that $50 \%$ of individuals allergic to compositae mix were sensitized to hydroperoxides of limonene, and $33.4 \%$ to colophonium. Interestingly, $50 \%$ of individuals allergic to compositae mix had positive patch test reactions to polysorbate 80 . No similar findings were available in literature. The sensitization rate for isopropyl myristate among dental students was low compared to other tested allergens $-7.5 \%$. It should be emphasized that $66.7 \%$ of the sensitized to isopropyl myristate individuals had positive patch test reactions to colophonium as well. Repeated applications of relatively low concentrations of parabens in medications and cosmetics may lead to sensitivity. Paraben mix is a mixture of 5 different paraben esters: methyl-, ethyl-, propyl-, butyl- and benzyl-parahydroxybenzoate. Two or more paraben esters are often found in one product (e.g. cosmetics, pharmaceutical creams, liquid soaps) so it is useful to test paraben sensitivity with paraben mix, as there is a high incidence of cross-reactions between the esters. In the present study, the sensitization rate to paraben mix among dental students was $12.5 \%$, but $80 \%$ from the sensitized to parabens exhibited positive skin patch test reactions to compositae mix as well. Healthcare settings often use antimicrobial/antiseptic hand wash products with high concentration of triclosan. The sensitization incidence to triclosan established in our study was the lowest observed in the group of dental students (5\%) and among the highest ones $(20 \%)$ in the group of dental patients. Furthermore, $100 \%$ of the sensitized to triclosan in the group of dental students and $75 \%$ of dental patients had concomitant positive reaction to polysorbate 80 , and $50 \%$ of the sensitized to triclosan from both groups exhibited concomitant positive reaction to hydroperoxides of limonene.

Further work is needed to validate reliability of the present findings. Proper occupational risk information and personal protection should be recommended for dental students.

\section{CONCLUSION}

Colophonium and polysorbate 80 could be outlined as sensitizers of paramount importance for both dental students and dental patients. We consider the major importance of the exposure to colophonium during the course of practical education in dentistry for the onset of the sensitization. Sensitization to compositae mix was observed only among dental students. We consider the leading role of consumer exposure for the onset of the sensitization to triclosan and to hydroperoxides of limonene. Unexpected and unreported reactions of concomitant sensitization were observed.

\section{Acknowledgements}

The study was granted by the Medical University, Sofia - Project No. 4-C/2014 "Pilot investigation of urinary bisphenol A in students of dental medicine, students from Dental Technician School and in dental professionals, exposed during the practical education". Manager of the project - Professor Angelina Ilieva Kisselova-Yaneva, D.D.S, PhD, D.Sc.

\section{Conflict of Interests}

None declared

\section{REFERENCES}

1. Hamilton T, de Gannes GC. Allergic contact dermatitis to preservatives and fragrances in cosmetics. Skin Therapy Lett. 2011;16(4):1-4. PubMed PMID

2. Park ME, Zippin JH. Allergic contact dermatitis to cosmetics. Dermatol Clin. 2014;32(1):1-11.

3. Kumar P, Paulose R. Patch testing in suspected allergic contact dermatitis to cosmetics. Dermatol Res Pract. 2014;2014:695387. doi: 10.1155/2014/695387.

4. Doukaki S, Pistone G, Aricó M, Bongiomo MR. Allergic contact dermatitis with contact urticaria to colophony from an alternative remedy. Dermatitis. 2012;23(6):298-99.

5. Hamstra AA, Jacob SE. A review of colophonium. The Dermatologist. 2015;23(8):38-41.

6. Schwarcz KD, Bajay MM, Macrini CM, Salazar VL, Souza AP, Pinheiro JB, et al. Microsatellite markers for the Cabreúva tree, Myroxylon peruiferum (Fabaceae), an endangered medicinal species from the Brazilian Atlantic Forest. Genet Mol Res. 2014;13(3):6920-5.

7. Kręcisz B, Chomiczewska-Skóra D, Kieć-Świerczyńska M. Preservatives as important etiologic factors of allergic contact dermatitis. Med Pr. 2015;66(3):327-32.

8. Bedoux G, Roig B, Thomas O, Dupont V, Le Bot B. Occurrence and toxicity of antimicrobial triclosan and by-products in the environment. Environ Sci Pollut Res Int. 2012;19(4):1044-65.

9. Ada S, Seçkin D. Patch testing in allergic contact dermatitis: is it useful to perform the cosmetic series in addition to the European standard series? J Eur Acad Dermatol Venereol. 2010;24(10):1192-6.

10. Zhang H, Dou J, Zhai Y, Liu A, Zhai G. Advances in the formulations of non-injection administration of docetaxel. J Drug Target. 2014;22(2):8794.

11. Bråred Christensson J, Andersen KE, Bruze M, Johansen JD, GarciaBravo B, Gimenez Arnau A, et al. Positive patch test reactions to oxidized limonene: exposure and relevance. Contact Dermatitis. 2014;71(5):26472 . 
12. Toholka R, Wang YS, Tate B, Tam M, Cahill J, Palmer A, et al. The first Australian Baseline Series: Recommendations for patch testing in suspected contact dermatitis. Australas J Dermatol. 2015;56(2):107-15.

13. European Agency for Safety and Healthy at Work. Young people and safety and work [Internet]. [cited 2018 Nov 24]. Available from: https:// osha.europa.eu/en/themes/young-workers.

14. Lyapina M, Krasteva A, Dencheva M, Tzekova M, Kisselova-Yaneva A. Methacrylate and acrylate allergy in dental students. J IMAB. 2013;19(4):359-66.

15. Lyapina M, Krasteva A, Dencheva M, Tzekova M, Deliverska M, Kisselova-Yaneva A. Comparative overall health status assessment of subjects with allergic contact dermatitis to formaldehyde and glutaraldehyde. Biotechnol Biotechnol Equip. 2013;27(6):4297-303.

16. Lyapina M, Dencheva M, Krasteva A, Tzekova M, Kisselova-Yaneva A Concomitant contact allergy to formaldehyde and methacrylic monomers in students of dental medicine and dental patients. Int J Occup Med Environ Health. 2014;27(5):797-807.

17. Lyapina M, Dencheva M, Krasteva A, Tzekova M, Deliverska M, Kisselova A. Pilot study of contact sensitization to formaldehyde-releasers, formaldehyde and glutaraldehyde in dental students. SANAMED. 2016;11(1):21-7.

18. Lyapina M, Krasteva A, Dencheva M, Tzekova M, Deliverska M, Kisselova A. Pilot study of contact sensitization to rubber allergens and bisphenol A in dental students. Int J Occup Med Environ Health. 2017;30(3):397-405.
19. Nix S. How resins protect trees and increase tree value [Internet]. New York: ThoughtCo; 2018 [cited 2018 Nov 24]. Available from: http:// forestry.about.com/od/timberproducts/a/What-Are-Tree-Resins.htm.

20. Belloni Fortina A, Cooper SM, Spiewak R, Fontana E, Schnuch A, Uter W. Patch test results in children and adolescents across Europe

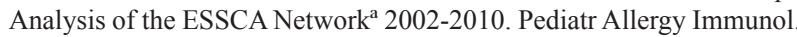
2015;26(5):446-55.

21. Siegel PD, Law BF, Fowler JF Jr, Fowler LM. Disproportionated rosin dehydroabietic acid in neoprene surgical gloves. Dermatitis. 2010;21(3):157-9.

22. Arribas MP, Soro P, Silvestre JF. Allergic contact dermatitis to fragrances: part 2. Actas Dermosifiliogr. 2013;104(1):29-37.

23. Diepgen TL, Ofenloch R, Bruze M, Cazzaniga S, Coenraads PJ, Elsner $\mathrm{P}$, et al. Prevalence of fragrance contact allergy in the general population of five European countries: a cross-sectional study. Br J Dermatol. 2015;173(6):1411-9.

24. Bansal R, Jain A. Overview on the current antibiotic containing agents used in endodontics. N Am J Med Sci. 2014;6(8):351-8.

25. Paulsen E, Andersen KE. Colophonium and Compositae mix as markers of fragrance allergy: cross-reactivity between fragrance terpenes, colophonium and compositae plant extracts. Contact Dermatitis. 2005;53(5):28591.

Received March 3, 2016

Accepted in revised form February 1, 2019 